\title{
CUSTOS RELACIONADOS COM A QUALIDADE: CONTRIBUTOS PARA O DESEMPENHO ORGANIZACIONAL
}

\author{
A. R. Pires ${ }^{1 *}$, M. Saraiva ${ }^{2}$ \\ 1 UNIDEMI, Unidade de Investigação do Departamente de Engenharia Mecânica e Industrial, Universidade Nova \\ de Lisboa, Portugal e Instituto Politécnico de Setúbal \\ 2 Universidade de Évora e BRU-UNIDE/ISCTE-IUL, Portugal antonio.pires@estsetubal.ips.pt \\ *antonio.pires@estsetubal.ips.pt
}

\section{RESUMO}

$\mathrm{Na}$ década de 60, a técnica dos Custos Relacionados com a Qualidade (CRQ) surge numa tentativa de provar que a qualidade contribuía para a rentabilidade, que não era um custo, mas um investimento. Porém, os CRQ deixaram de ser contabilizados, dado que os modelos ficaram obsoletos, os benefícios são inquestionáveis e o uso da informação tem sido diminuta e pouco útil para as organizações. Porém, a sociedade do conhecimento e da aprendizagem e as dinâmicas empresariais colocam o problema dos CRQ noutro patamar de análise. Com este artigo pretende-se levantar um conjunto de questões, tais como: as dimensões e as formas de gestão no quadro de alianças, ou outras novas soluções organizacionais; como avaliar os custos da gestão por processos e o valor dos ativos intangíveis; e que custos podem/devem ser autonomizados, que de modo útil suportem as decisões. A quantificação dos CRQ veio estabelecer o elo de ligação destes com os resultados operacionais e financeiros, revelando qua a qualidade aumenta o desempenho das empresas. Todavia, as abordagens aos CRQ necessitam de ser repensadas e desenvolvidas para poderem responder às novas realidades organizacionais. Algumas perspetivas são avançadas e outros desafios são propostos aos investigadores da qualidade e da produção, porque se concluiu existirem potencialidades ainda não exploradas.

PALAVRAS-CHAVE: Custos, Qualidade, Tecnologia, Processo, Lean.

\section{QUALITY-RELATED COSTS: CONTRIBUTION TO ORGANIZATIONAL PERFORMANCE}

\begin{abstract}
In the 1960s, the technique of Quality-Related Costs (QRCs) arose in an attempt to prove that quality contributed to profitability, which was not a cost but an investment. However, QRCs are no longer counted, since the models have become obsolete, the benefits are unquestionable, and the use of information has been small and of little use to organizations. However, the knowledge and learning society and the entrepreneurial dynamics place the QRCs problem on another level of analysis. This article intends to raise a set of issues, such as: the dimensions and forms of management in the framework of alliances, or in other new organizational
\end{abstract}

solutions; how to assess the costs of process management and the value of intangible assets; and what costs can / should be made autonomous, in a useful way to support management decisions. The quantification of the QRCs established the link between them and the operational and financial results, revealing how quality increases the performance of companies. However, approaches to QRCs need to be rethought and developed to respond to new organizational realities. Some perspectives are advanced and other challenges are proposed to quality and production researchers, because it has been concluded that there are still unexplored potentialities.

KEYWORDS: Costs, Quality, Technology, Process, Lean. 


\section{INTRODUÇÃO}

Os "qualidistas" têm usado um conjunto vasto e, por vezes, pouco integrado e coerente de técnicas e métodos de controlo e gestão da qualidade, para responderem aos desafios da qualidade, da produtividade e da competitividade. Lillrank e Kano (1989) designam essas técnicas e métodos por "Conglomerado da qualidade" (e.g. Reengenharia, JIT, Planeamento do marketing, Lean, 6 Sigma).

Porém, os resultados nem sempre têm convencido, dado que, na tentativa de provar que a qualidade contribuía para a Rentabilidade, que não era um custo, mas um investimento, os "qualidistas" criaram, a partir da década de 60, a técnica dos Custos Relacionados com a Qualidade (CRQ), com base em referências e trabalhos anteriores. Contudo, os CRQ deixaram de ser contabilizados por duas razões: por um lado, os modelos ficaram obsoletos, devido à dinâmica dos sistemas (Juran, 1988; Pires, 1993), e, por outro, já não interessa a sua contabilização dado que são inquestionáveis (Antunes, 1998). Por exemplo, o nível ótimo para a qualidade (também intitulado de nível económico), numa sociedade do conhecimento e da aprendizagem, encontra analogia com o nível ótimo, onde se colocam as decisões, estando este relacionado com a informação e a competência aí disponíveis (Jensen e Meckling, 1995).

Igualmente as preocupações de curto prazo, típicas das dinâmicas empresariais em situações de grande incerteza e instabilidade, têm conduzido a desvalorizar as abordagens planeadas e sistemáticas, que caracterizam os sistemas da qualidade. Esta situação tem tido implicações na relevância atribuída às técnicas e métodos de controlo e gestão da qualidade, vistas com frequência como tornando os processos mais difíceis e onerosos.

Assim, importa revisitar os conceitos e práticas dos CRQ, na perspetiva de renovar abordagens e justificar as vantagens económicas e os investimentos na qualidade ao nível dos produtos, processos e soluções organizacionais.

Neste sentido, este artigo, inicialmente, apresenta um enquadramento histórico para a temática em análise, os Custos Relacionados com a Qualidade (CRQ). Posteriormente, estabelecese uma ligação entre a Qualidade, Rentabilidade e CRQ, apresentando as limitações ao modelo clássico, a abordagem dinâmica, o Lean e 6 Sigma, bem como são evidenciadas as novas dimensões para os CRQ. No final, são efetuadas as considerações finais e apresentadas algumas questões remanescentes.

\section{ENQUADRAMENTO HISTÓRICO PARA OS CUSTOS RELACIONADOS COM A QUALIDADE}

A temática dos CRQ iniciou-se com a determinação do nível ótimo da qualidade (económico) por Rutherford (1948). Seguidamente, Juran (1951) e Feigenbaum (1957) referiram que a qualidade é mais um investimento seguro do que um custo. Em 1957, surge a primeira classificação dos custos da qualidade segundo o modelo PAF (Prevenção, Avaliação e Falhas) (Feigenbaum, 1957; Masser, 1957). O Comité Técnico dos Custos da Qualidade da American Society for Quality atribui o esquema de classificação nas 4 categorias a Masser, todavia, o artigo de Feigenbaum surgiu primeiro. Entre o final dos anos 80 e o final dos anos 90, do século XX, diversos autores abordaram os conceitos, práticas e métodos dos CRQ nas suas publicações, tal como se pode observar no Quadro 1, que apresenta a evolução histórica desses conceitos. No Anexo I apresenta-se as respetivas referências. 
Quadro 1 - Evolução histórica dos conceitos de CRQ

\begin{tabular}{|c|c|c|}
\hline Data & Autor & Conceitos \\
\hline 1948 & Rutherford & $\begin{array}{l}\text { Nível ótimo da qualidade (económico): A partir de um certo } \\
\text { ponto, não são significativas as reduções dos custos, com o } \\
\text { aumento das atividades do controlo da qualidade }\end{array}$ \\
\hline $\begin{array}{l}1951 \\
1956 \\
\end{array}$ & $\begin{array}{l}\text { Juran } \\
\text { Feigenbaum }\end{array}$ & A qualidade é mais um investimento seguro do que um custo \\
\hline $\begin{array}{l}1957 \\
1957\end{array}$ & $\begin{array}{l}\text { Feigenbaum } \\
\text { Masser }\end{array}$ & $\begin{array}{l}\text { Pela primeira vez classificavam os custos da qualidade nas } \\
\text { categorias de Prevenção, Avaliação, Falhas Internas e Falhas } \\
\text { Externas, como hoje são entendidos. }\end{array}$ \\
\hline 1963 & Norma MIL-Q-9858A & $\begin{array}{l}\text { "Requisitos dum programa da qualidade" - exige que nos } \\
\text { contratos governamentais, os fornecedores e subfornecedores } \\
\text { utilizassem os CRQ como um elemento da gestão da qualidade }\end{array}$ \\
\hline 1964 & ASQC & \\
\hline 1967 & $\begin{array}{l}\text { Secretaria de Defesa } \\
\text { para Instalações e } \\
\text { Logística }\end{array}$ & Estrutura para os sistemas dos CRQ \\
\hline 1979 & Crosby & Os CRQ serão minimizados por fazer bem à primeira \\
\hline 1981 & Tassinari & Custos de lançamento de um produto \\
\hline 1982 & Deming & $\begin{array}{l}\text { Argumenta que a ênfase na avaliação dos custos, e na procura de } \\
\text { níveis ótimos de defeitos, é uma prova de falha no entendimento } \\
\text { do problema de competitividade }\end{array}$ \\
\hline 1983 & Sullivan e Owens & $\begin{array}{l}\text { Confirmar que o relatório dos custos da qualidade é tipicamente } \\
\text { limitado aos itens relacionados com a produção, estando omissos } \\
\text { os custos da qualidade das funções de áreas administrativas }\end{array}$ \\
\hline $\begin{array}{l}1984 \\
1986\end{array}$ & $\begin{array}{l}\text { Aker } \\
\text { Danforth }\end{array}$ & $\begin{array}{l}\text { Estimam que os custos da não qualidade das áreas não produtivas } \\
\text { representam } 20 \text { a } 50 \% \text { do total da previsão para estas funções. }\end{array}$ \\
\hline 1988 & Plunkett and Dale & $\begin{array}{l}\text { Pouca pesquisa se efetuou na medição, utilização, ou gestão dos } \\
\text { seus efeitos económicos da qualidade }\end{array}$ \\
\hline 1990 & Campanella & $\begin{array}{l}\text { Os custos da não-qualidade como um enorme iceberg, em que a } \\
\text { parte flutuante, visível, é constituída pelos desperdícios, retornos } \\
\text { da produção e garantias, sendo estes custos os normalmente } \\
\text { medidos. A parte submersa é constituída por tempos de } \\
\text { engenharia, tempos de gestão, perda de capacidade e de } \\
\text { encomendas, os custos ocultos da qualidade. }\end{array}$ \\
\hline $\begin{array}{l}1983, \\
1984\end{array}$ & Kaplan & \\
\hline 1987 & Howell e Soucey & $\begin{array}{l}\text { As práticas tradicionais de contabilidade de gestão são alvo de } \\
\text { críticas por se mostrarem inadequadas aos novos processos de }\end{array}$ \\
\hline 1988 & Berliner e Brimson & \\
\hline 1991 & & \\
\hline
\end{tabular}




\begin{tabular}{|c|c|c|}
\hline Data & Autor & Conceitos \\
\hline 1987 & $\begin{array}{l}\text { Morse et al } \\
\text { Simpson e Muther } \\
\text { Atkinson et al }\end{array}$ & $\begin{array}{l}\text { Várias sugestões são feitas aos contabilistas para que estes } \\
\text { possam contribuir para a melhoria da qualidade, sendo a } \\
\text { quantificação e os relatórios dos custos relacionados com a } \\
\text { qualidade, de longe, a mais citada. }\end{array}$ \\
\hline 1987 & Taguchi & $\begin{array}{l}\text { Função de perdas: perda monetária imposta à sociedade a partir } \\
\text { do momento em que um produto é distribuído. }\end{array}$ \\
\hline 1991 & Rooney e Rogerson & $\begin{array}{l}\text { Custos da organização e do departamento da qualidade e, por } \\
\text { outro lado, os custos relativos a um produto ou projeto. }\end{array}$ \\
\hline 1990 & BS 6143 - Parte 2 & $\begin{array}{l}\text { Abordagem tradicional em que a tipologia dos elementos de } \\
\text { custo em Prevenção, Avaliação e Falhas }\end{array}$ \\
\hline 1993 & Pires & $\begin{array}{l}\text { Quanto maior for o domínio da técnica dos CRQ, menor será o } \\
\text { desperdício e os prejuízos tenderão a diminuir, pelo que a gestão } \\
\text { da qualidade se justifica a si própria }\end{array}$ \\
\hline 1994 & NP 4239 & $\begin{array}{l}\text { Abordagem tradicional em que a tipologia dos elementos de } \\
\text { custo em Prevenção, Avaliação e Falhas }\end{array}$ \\
\hline 1995 & Dale e Plunkett & $\begin{array}{l}\text { Insistem na necessidade de um esforço conjunto entre as funções } \\
\text { "qualidade" e "contabilidade" e alertam para o facto, de que } \\
\text { qualquer que seja o método e os critérios adotados, o custeio da } \\
\text { qualidade dificilmente pode ser exato. }\end{array}$ \\
\hline 1986 & Fine & $\begin{array}{l}\text { Modelo, demonstrando que na medida em que as atividades da } \\
\text { qualidade são mais eficazes, a curva dos custos de conformidade } \\
\text { e, por consequência, a dos custos totais sofrem os deslocamentos } \\
\text { positivos }\end{array}$ \\
\hline $\begin{array}{l}1986, \\
1988\end{array}$ & Schneiderman & $\begin{array}{l}\text { Defensores da filosofia "zero defeitos". As empresas } \\
\text { empenhadas na melhoria contínua, com um nível fixo de gastos } \\
\text { nas atividades de conformidade, obtêm reduções nos custos da } \\
\text { não conformidade, à medida que as equipas de melhoria contínua } \\
\text { prosseguem com a identificação e eliminação dos problemas da } \\
\text { qualidade. }\end{array}$ \\
\hline 1991 & $\begin{array}{l}\text { Departamento de } \\
\text { Defesa dos EUA }\end{array}$ & Custo do ciclo de vida \\
\hline 1993 & Juran e Gryna & $\begin{array}{l}\text { Reconhece que os desenvolvimentos tecnológicos tornaram o } \\
\text { objetivo "zero defeitos" realizável }\end{array}$ \\
\hline 1993 & Blame & \\
\hline 1993 & Smith & $\begin{array}{l}\text { Melhorias da qualidade, o custo total da qualidade diminui } \\
\text { havendo uma altura, talvez no futuro, em que se poderá falar do } \\
\text { preço de reduzir o último defeito }\end{array}$ \\
\hline 1993 & Millar & \\
\hline 1993 & Murray & $\begin{array}{l}\text { Identifica três grandes áreas da qualidade: negativa, aceitável e } \\
\text { positiva (atrativa) e relaciona-as com os custos da não-qualidade } \\
\text { / vantagem competitiva }\end{array}$ \\
\hline
\end{tabular}




\begin{tabular}{|c|l|l|}
\hline Data & \multicolumn{1}{|c|}{ Autor } & \multicolumn{1}{c|}{ Conceitos } \\
\hline 1994 & Bester & $\begin{array}{l}\text { Retoma uma abordagem economicista na medida em que } \\
\text { defende que os recursos económicos são sempre escassos e que a } \\
\text { sua aplicação não pode ser feita em investimentos cuja } \\
\text { rentabilidade tem algo de intangível. Assume, também, que } \\
\text { falhas existirão sempre, e que é necessário conviver com elas, } \\
\text { gerindo o nível a que elas se situam. }\end{array}$ \\
\hline 2017 & $\begin{array}{l}\text { Pires, Novas, Saraiva } \\
\text { e Coelho }\end{array}$ & Uso da informação relativa aos CRQ pelas empresas Portuguesas \\
\hline
\end{tabular}

Fonte: Elaboração própria

Ao longo destas investigações foram sendo utilizados vários modelos, para facilitar a quantificação, dos quais se destacam: Modelo Prevenção, Avaliação e Falhas (PAF); Modelo de custo do processo; Modelo baseado nos tempos de execução; Modelo de perdas; Modelo de produções unitárias; e Modelo da Função de Perda de Taguchi.

A análise clássica dos custos baseia-se no facto de que alguns grupos de custos poderem, e deverem, ser encarados como um investimento para reduzir outros custos.

Estes trabalhos teóricos sustentam que as melhorias da qualidade podem ser obtidas ao longo do tempo, com custos de conformidade fixos e até reduzidos. Fine (1986) desenvolveu um modelo, demonstrando que na medida em que as atividades da qualidade são mais eficientes e eficazes, por exemplo, com base na formação, a curva dos custos de conformidade e, por consequência, a dos custos totais sofrem deslocamentos, conforme Figura 1.

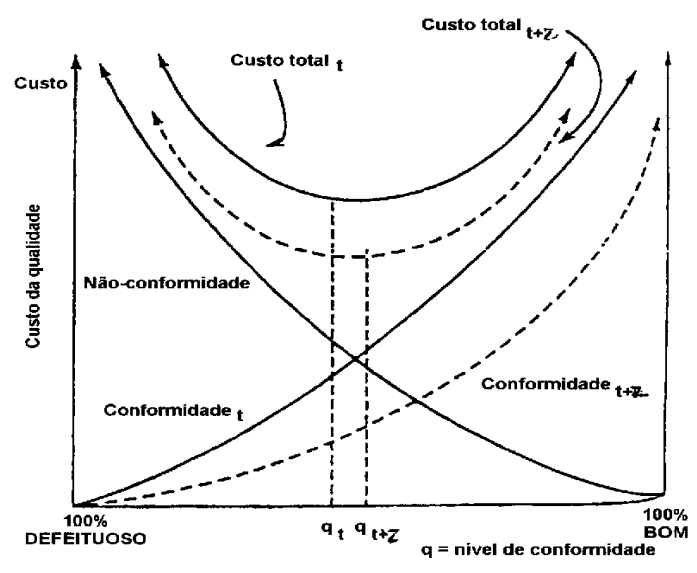

Figura 1: Impactes da formação

Fonte: Fine (1986)

Juran e Gryna (1993) reconhecem que os desenvolvimentos tecnológicos tornaram o objetivo "zero defeitos" realizável, evoluindo da posição assumida em 1951.

Crosby (1979), considerando este objetivo atingível, e reconhecendo que a melhoria da qualidade obtida através do aumento do nível de inspeção elevaria os custos, insiste que a 
metodologia para a obtenção de zero defeitos se baseia na otimização das técnicas de prevenção. A sua interpretação da curva dos custos de conformidade está de acordo com a Figura 2.

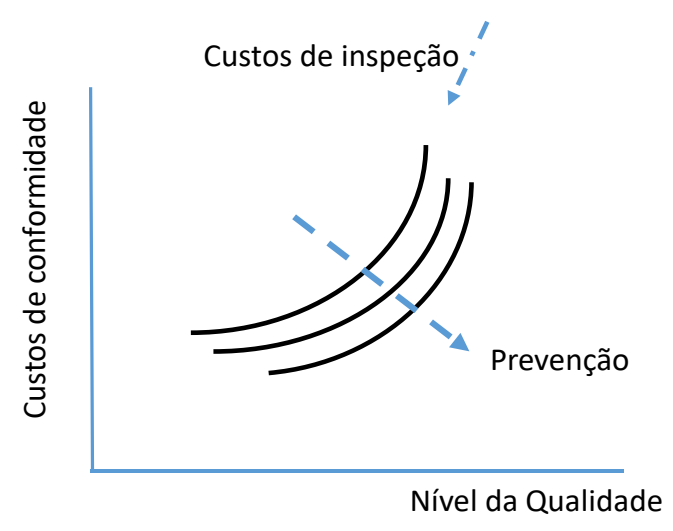

Figura 2: Otimização pela prevenção

Fonte: Crosby (1979)

Bester (1994) perspetiva uma abordagem diferente, algo economicista na medida em que defende que os recursos económicos são sempre escassos e que a sua aplicação não pode ser feita em investimentos cuja rentabilidade tem algo de intangível. Assume, também, que falhas existirão sempre, e que é necessário conviver com elas, gerindo o nível a que elas se situam.

Os gráficos de evolução de custos são um bom exemplo de análise e deteção de tendências. A relação entre os custos de Prevenção, Avaliação e Falhas referente à qualidade, bem como os desenvolvimentos/melhorias da qualidade (após implementação dum sistema da qualidade) pode ser evidenciada na Figura 3.

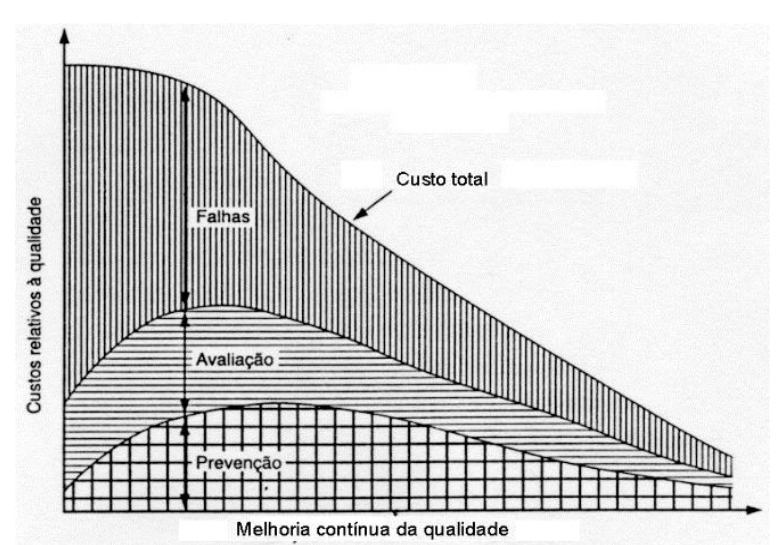

Figura 3: Evolução dos custos da qualidade

Fonte: BS 6143: Part 1 (1992)

Apesar da importância das atividades de Prevenção e Avaliação para a melhoria da qualidade, ser largamente reconhecida, alguns gestores questionam-na, ao verem aumentados os custos de conformidade. 
Schneiderman (1986, 1988) e Dawes e Campanella (1989), defensores da filosofia "zero defeitos", argumentam que empresas empenhadas na melhoria contínua, com um nível fixo de gastos nas atividades de conformidade, obtêm reduções nos custos da não conformidade, à medida que as equipas de melhoria contínua prosseguem com a identificação e eliminação dos problemas da qualidade.

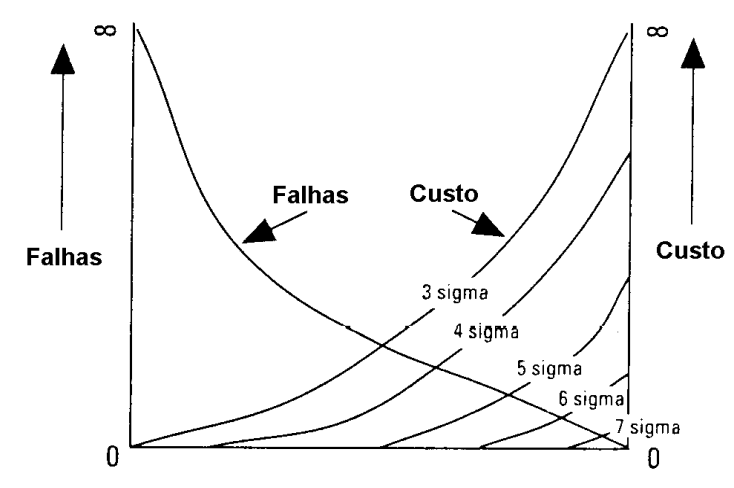

Figura 4: Modelo dinâmico

Fonte: Schneiderman (1986, 1988) e Dawes e Campanella (1989)

Contrariando os modelos clásicos, a melhoria da capacidade da conceção e prevenção, aproxima a qualidade de níveis ótimos, enquanto os custos diminuem firmemente (Figura 4).

Entre os modelos clássicos e os dinâmicos pode-se considerar, segundo Murray (1991), três grandes áreas da qualidade: negativa, aceitável e positiva (atrativa), representadas na Figura 5.

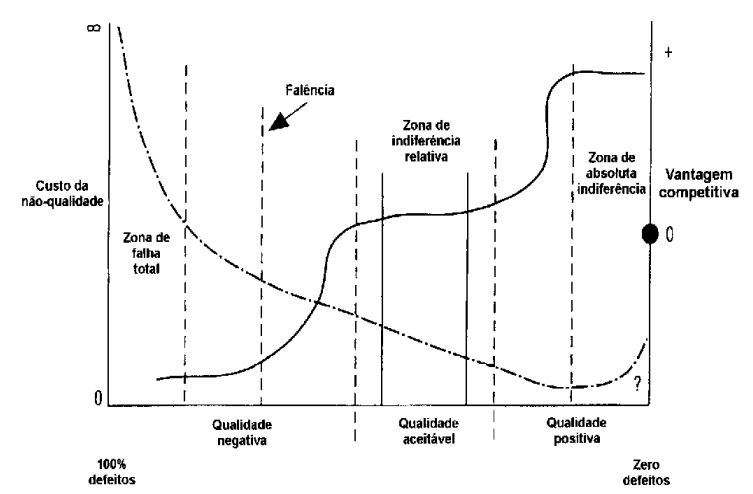

---- Custos _ Vantagem competitiva

Figura 5: Custos da não-qualidade / vantagem competitiva

Fonte: Murray (1991)

Existem organizações a operar numa zona de absoluta indiferença para a maioria dos seus clientes, e os custos da não-qualidade continuam a diminuir, pois é sempre possível encontrar formas de melhorar a qualidade, reduzir o tempo de ciclo e o custo. 
Os movimentos atuais em direção à Excelência evidenciam o resultado do alargamento da consciência da importância, do empenhamento, das organizações na persecução da excelência, porque desta procura resulta um fluxo constante de melhoria e inovação (Pires, 2016).

\section{QUALIDADE, RENTABILIDADE E CRQ}

A quantificação dos CRQ veio estabelecer o elo de ligação destes com os resultados operacionais e financeiros, revelando que a qualidade aumenta a rentabilidade das empresas.

$\mathrm{Na}$ realidade, as aplicações do custeio da qualidade são numerosas e diversificadas, dependendo das necessidades da organização. A sua utilidade pode ser encarada de quatro perspetivas diferentes:

1. Veículo de identificação e correção de ineficiências;

2. Apoio à consolidação do sistema da qualidade;

3. Fator de planeamento e orçamentação; e

4. Elemento de motivação para um melhor desempenho.

Em algumas empresas, o custo da qualidade é medido pelo rendimento (yield) e pela produtividade (unidades produzidas por hora direta de trabalho) das operações produtivas, deixando de existir a atividade dos custos da qualidade, pois na consecução dos objetivos, a não-qualidade pode ser o desvio dos objetivos.

A envolvente competitiva tem pressionado as organizações para resultados de curto prazo, levando muitos gestores a ficarem constrangidos, quando os benefícios tangíveis não surgem neste prazo, o que dificulta a contabilização e utilização dos CRQ.

Contudo, para muitas empresas, a sua sobrevivência passa por reduções de custo substanciais, o que parece contraditório com aquele posicionamento. O primeiro passo consistiria na identificação do desperdício e nas atividades que não acrescentam valor.

\subsection{Limitações ao modelo clássico}

O modelo clássico está muito datado, e não responde a outras dinâmicas organizacionais mais influenciadoras do desempenho, tais como:

a) Assume que o produtor tem controlo sobre todas as categorias de custos, o que nem sempre acontece, quer a montante nos fornecedores, quer a jusante na cadeia de distribuição. As novas formas de organização (ex: alianças, empresas virtuais, redes) trazem novas exigências;

b) Não se adapta facilmente a produções unitárias, onde os custos de avaliação podem ser muito determinados pelos clientes, a prevenção é condicionada pela experiência e pela novidade, e onde os custos das falhas recaem em grande parte no cliente;

c) Associa um nível da qualidade a um custo total mínimo, contrariando o princípio da melhoria contínua (quando será sempre possível melhorar o nível e baixar os custos). Embora o modelo seja útil, quando utilizado para caracterizar a situação num momento determinado, não serve para monitorizar o progresso;

d) Assume um ponto ótimo na curva dos custos totais da qualidade num ponto anterior aos 100 $\%$ de conformidade, ou seja, admite a existência de um certo nível de produtos defeituosos 
como a situação ideal em termos económicos, aspeto que não merece aceitação na envolvente competitiva;

e) Adicionalmente, duas lacunas estruturais não aconselham a sua adoção: 1) Não fomenta o objetivo de eliminar totalmente as falhas externas (objetivo essencial de um Sistema de Gestão da Qualidade); 2) não incorpora as atividades que não acrescentam valor nas restantes (para além da qualidade) funções das organizações, nem o conceito de desperdício (ex.: tempo, materiais, recursos), áreas onde se situam valores muito mais elevados e impactantes dos resultados. O movimento da qualidade tem vindo, justamente a incorporar no seu "conglomerado" de técnicas e métodos, aqueles que mais diretamente revelam os custos do desperdício e das atividades que não acrescentam valor (ex.: JIT, Lean, 6 Sigma).

f) Por último, a dinâmica dos negócios nem sempre permite acomodar as vantagens das técnicas e métodos mais desenhados para situações de instabilidade, pelo que, a diminuição de custos pode não ser a prioridade num determinado momento. Por exemplo: 1) a necessidade de proceder a aumentos da produção por exigência da procura pode conduzir à necessidade de implementar processos com custos mais elevados; 2) o fabrico de novos produtos, devido ao facto de os processos de fabrico ainda não estarem estabilizados, pode ser acompanhado de um aumento dos custos.

\subsection{Abordagem Dinâmica}

Pelo exposto, têm surgido outras abordagens que incorporam a melhoria contínua e a dinâmica de movimento, em contraposição ao posicionamento. A Figura 6 ilustra os conceitos básicos: 1) Os custos de prevenção podem baixar, não só os custos das falhas, mas também os custos da avaliação. Este conceito tem fundamentos, quer na evolução tecnológica dos métodos de inspeção / verificação / controlo, quer na conceção de métodos de fabrico / prestação do serviço mais robustos e desempenhados por pessoas mais qualificadas; e 2) os próprios custos de prevenção podem baixar, se se tiver em conta a experiência acumulada, as lições aprendidas e o incremento no conhecimento. Contudo, algumas das limitações do modelo clássico, também se mantêm.

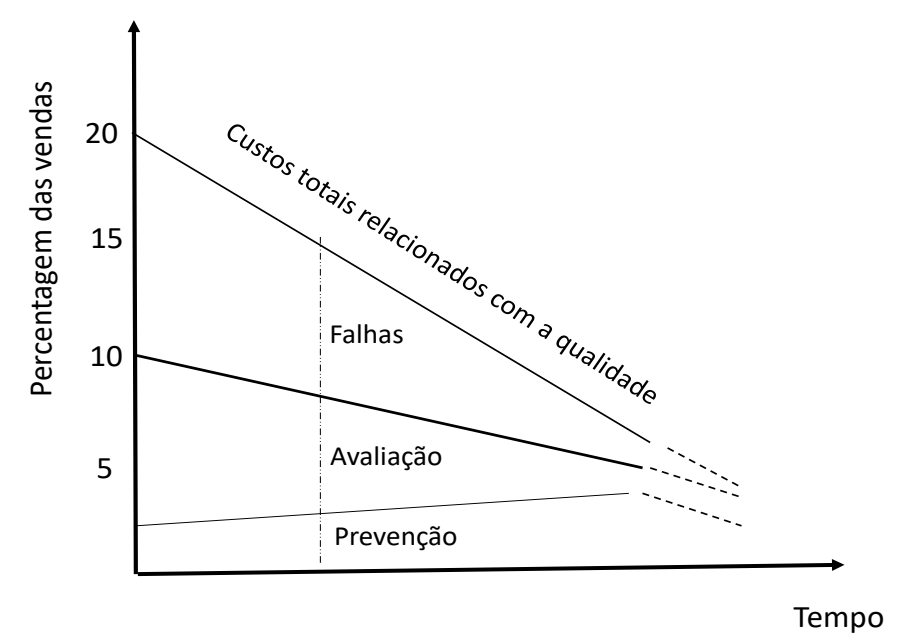

Figura 6: Visão dinâmica e melhoria contínua

Fonte: Pires (1993) 
Porém, a representação gráfica ajuda a caracterizar e diagnosticar as situações existentes e a encontrar novas formas de realização de modo mais eficaz.

O Quadro 2 apresenta resumidamente as características das formas de representação dos processos.

Quadro 2: Características das formas de representação dos processos

\begin{tabular}{|c|c|c|c|c|}
\hline 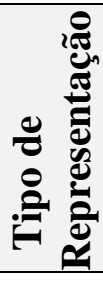 & 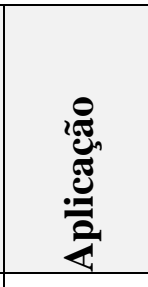 & 宽 & Características & Pontos-chave \\
\hline 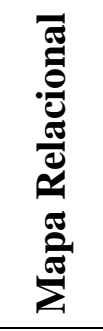 & 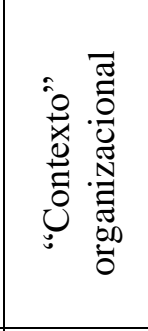 & . & $\begin{array}{l}\text { Evidencia as relações } \\
\text { cliente fornecedor internas. } \\
\text { Define a estrutura } \\
\text { organizacional }\end{array}$ & $\begin{array}{l}\text { - Não define o processo no seio da área funcional } \\
\text { - Mostra as relações existentes na organização } \\
\text { - Define as relações cliente/fornecedor }\end{array}$ \\
\hline 㺼 & 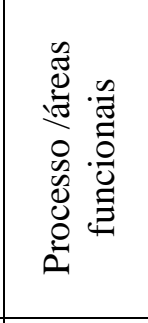 & 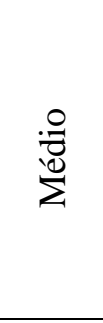 & $\begin{array}{l}\text { Mostra as áreas funcionais, } \\
\text { as atividades e a sua } \\
\text { sequência. }\end{array}$ & $\begin{array}{l}\text { - Define o processo no seio da área funcional } \\
\text { - Mostra as relações cliente/fornecedor } \\
\text { - Define os subprocessos e/ou atividades que integram } \\
\text { o processo }\end{array}$ \\
\hline 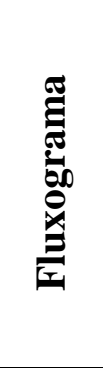 & 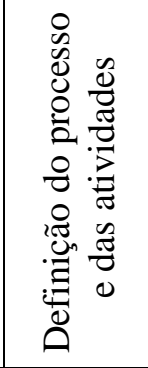 & 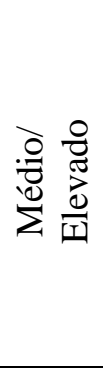 & $\begin{array}{l}\text { Mostra as atividades e a } \\
\text { sua sequência. } \\
\text { Define o tipo e as } \\
\text { características da atividade }\end{array}$ & $\begin{array}{l}\text { - Define as atividades que integram o processo e a sua } \\
\text { sequência possível } \\
\text { - Caracteriza o tipo de atividade } \\
\text { - Não define diretamente quem realiza a atividade mas } \\
\text { esta informação pode ser associada ao fluxograma } \\
\text { - Define o estado atual do processo }\end{array}$ \\
\hline 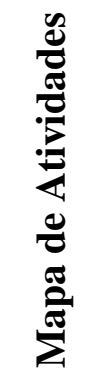 & 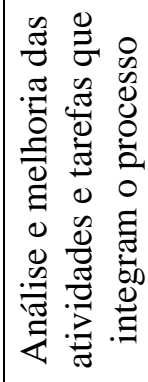 & $\begin{array}{l}\frac{0}{0} \\
\frac{\pi}{0} \\
\frac{0}{1}\end{array}$ & $\begin{array}{l}\text { Define as características e } \\
\text { os parâmetros específicos } \\
\text { das atividades e tarefas que } \\
\text { integram o processo }\end{array}$ & $\begin{array}{l}\text { - Define detalhadamente todas as atividades que } \\
\text { integram o processo, os seus parâmetros e } \\
\text { características } \\
\text { - Permite analisar as diferentes atividades } \\
\text { identificando e fornecendo entradas para a melhoria } \\
\text { do processo em termos operacionais }\end{array}$ \\
\hline 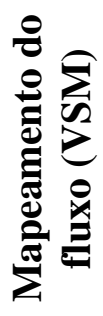 & 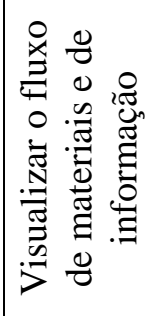 & 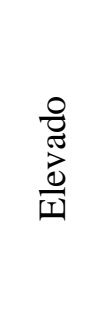 & $\begin{array}{c}\text { Expõe o desperdício dos } \\
\text { processos atuais e fornece } \\
\text { um roteiro para a melhoria } \\
\text { no futuro }\end{array}$ & $\begin{array}{l}\text { - Diagnóstico do processo através do cálculo de várias } \\
\text { variáveis dos processos e suas atividades }\end{array}$ \\
\hline
\end{tabular}




\subsection{Lean e 6 Sigma}

A melhoria dos processos pode ser apoiada nas metodologias Lean e 6 Sigma. Estas metodologias têm vindo a ser aplicadas com sucesso também nas áreas de serviço e de administração das empresas industriais e incluem:

- Técnicas para melhoria de fluxos, redução da variabilidade, redução de desperdícios, tempo de ciclo e da instabilidade dos processos produtivos e logísticos;

- Métodos de gestão orientados para o aumento sistemático do desempenho das organizações;

- E também como estratégia de negócio.

Os benefícios obtidos com estas metodologias estão abundantemente ilustradas na literatura (Domingues et al, 2016; Suzaki, 2010; Salvada et al, 2016).

O modelo DMAIC organiza estas técnicas e métodos em cinco fases distintas (Montgomery, 2009; Brook, 2010; Pereira, Tenera e Wemans (2013); Khandekar e Sulakhe, 2014):

1. Definir - esboçar o projeto, quais os seus objetivos, quais as datas associadas ao mesmo e qual a equipa que participará na sua realização.

2. Medir - estabelecer métricas e recolher os dados necessários e adequados à avaliação.

3. Analisar - analisar os dados obtidos de forma a determinar as causas dos problemas encontrados para que a melhoria do processo seja mais facilmente atingida.

4. Improve (melhorar) - definir quais as melhorias e alterações necessárias no processo para que a sua performance melhore e exista redução da variabilidade.

5. Controlar - garantir que a as melhorias implementadas no sistema se mantem a longo prazo.

Algumas questões específicas colocam-se nestas áreas, de que são exemplo a contabilização dos custos dos desperdícios (ex. sobreprodução, espera, transporte, movimento, processamento em excesso, stocks, defeitos); os benefícios das melhorias (ex. redução de atividades sem valor acrescentado); e as taxas de melhor utilização dos recursos (ex. alteração de fluxos, informatização).

\section{NOVAS DIMENSÕES PARA OS CUSTOS RELACIONADOS COM A QUALIDADE}

A disponibilidade tecnológica tende a enriquecer os produtos com novas funcionalidades. Só que, em muitos casos, os produtos ficam demasiado complexos, não amigáveis e os manuais de instruções são praticamente ilegíveis.

As profundas transformações nas tecnologias disponíveis, e na globalização dos mercados, estão a acarretar alterações frequentes e drásticas nos métodos de trabalho e de organização das atividades produtivas e de prestação de serviços. Os custos relacionados com estas transformações, e em particular os CRQ, precisam de algum tipo de quantificação, como forma de validar opções, riscos e oportunidades. A questão que se coloca, quando se equacionam os CRQ, tem a ver com os custos que não acrescentam valor ao cliente, ou à própria organização.

Por outro lado, a competitividade move-se cada vez mais para as fases anteriores ao fabrico ou à prestação do serviço, embora os recursos alocados a estas fases continuem escassos, em função do seu impacto nos resultados. Sabe-se que a maioria dos CRQ têm origem antes do fabrico / prestação do serviço (Pires, 2012; Khandekar e Sulakhe, 2014).

A produtividade tem vindo a ser avaliada duma forma global, o que não permite análises parcelares, nomeadamente determinar o impacto de cada área na produtividade global. Relembra-se 
que nas áreas não produtivas, a taxa de crescimento da produtividade é claramente inferior à verificada nas áreas produtivas. Os CRQ têm aqui um grande potencial de aplicação.

Assim, a competitividade é avaliada de forma imprecisa, frequentemente confundida com a produtividade, pelo que importa obter dados e informações que identifiquem, quer as áreas de melhoria na produtividade (ex.: redução de custos unitários), e da qualidade (ex.: redução de desperdícios e produtos defeituosos), quer na competitividade (ex.: quota de mercado e de crescimento).

A questão de saber até que ponto os custos relacionados com a qualidade (medida tradicional do desempenho da qualidade) pode ser uma medida de desempenho do processo de negócio continua sem respostas convincentes. Embora esta questão tenha sido intensamente discutida nos últimos anos, infelizmente, nem o movimento da qualidade, nem o mundo da contabilidade de gestão deram respostas suficientes.

Os resultados da pesquisa realizada por Sullivan e Owens (1983) vêm confirmar que o relatório dos custos da qualidade é tipicamente limitado aos itens relacionados com a produção. A omissão dos custos da qualidade das funções de áreas administrativas (ex.: compras, contabilidade, marketing e controlo da produção) é muito frequente. Estudos realizados pela IBM (Akers, 1984) e Westinghouse (Danforth,1986) estimam que estes custos representam 20 a 50\% do total da previsão para estas funções. Os resultados da aplicação das metodologias lean seis sigma mostram de forma contundente níveis de desperdício com muita frequência e facilidade acima dos $50 \%$ dos custos totais.

Os custos das oportunidades de vendas perdidas devido à má qualidade, também são muitas vezes omitidos.

O controlo diário dos processos requer informações rigorosas, no momento certo. As informações financeiras, especialmente os relatórios dos CRQ, vulgarmente, surgem mais tarde do que o pretendido, e muito agregados. Mais, a capacidade de resolução de problemas, baseada na informação dos CRQ, é muito limitada. Podem-se identificar áreas com problemas, mas muito dificilmente se encontra a causa dos problemas através deles.

Quando a libertação de recursos por melhor utilização em particular e com a melhoria em geral, surge o conceito de Função de Ganho que poderia ajudar a responder a outras questões como os benefícios das oportunidades (por oposição a Custos da Não Qualidade), os impactes positivos no ambiente, ou benefícios para a empresa/sociedade (por oposição à Função de Perdas). O quadro 3 ilustra esta perspetiva.

Por exemplo, pode-se falar de Ganhos de valor quando as alterações no fluxo do processo e/ou outras melhorias incrementam as atividades que acrescentam valor na totalidade das atividades.

Por último, os CRQ poderiam ser agregados em duas funções: a de perda e a de ganho. Em termos gráficos aproximados, a curva hiperbólica começaria no ponto ideal de $100 \%$ de atividades que acrescentam valor até $100 \%$ de atividades sem valor, como ilustrado na Figura 7. A parte central da curva representa níveis elevados de desempenho, permitindo encontrar fatores diferenciadores de competitividade. A eliminação de atividades que não acrescentam valor fora de um quadro de inovação pode traduzir-se em riscos elevados, tendo em conta que os processos de suporte podem ficar deteriorados.

As funções de valor, em que se relacionam perdas e ganhos podem ser outras fontes de partida para a investigação. 
Quadro 3 - Novas perspetivas para os custos relacionados com a qualidade

\begin{tabular}{|c|c|}
\hline TEMA & Justificação e Descrição \\
\hline \multicolumn{2}{|r|}{ Custos de Desenvolvimento e Progresso (Oportunidades) } \\
\hline $\begin{array}{l}\text { Desenvolvimento } \\
\text { tecnológico }\end{array}$ & $\begin{array}{l}\text { Equipamentos, hardware, software, qualificação das pessoas, conhecimentos e } \\
\text { competências. A introdução de novas tecnologias pode derivar da necessidade de } \\
\text { acompanhar o progresso e não de necessidades produtivas. }\end{array}$ \\
\hline $\begin{array}{l}\text { Desenvolvimento da } \\
\text { organização }\end{array}$ & $\begin{array}{l}\text { Qualificações, parcerias, otimização de processos, hardware, software } \\
\text { Níveis mais elevados de desempenho podem acarretar investimentos significativos }\end{array}$ \\
\hline Conceção e inovação & $\begin{array}{l}\text { Estudos de mercado, identificação de necessidades, conceção e desenvolvimento. } \\
\text { A competitividade desloca-se para as fases anteriores ao fabrico/prestação dos serviços, pelo } \\
\text { que importa avaliar a rentabilidade dos recursos afetos. }\end{array}$ \\
\hline $\begin{array}{l}\text { Comunicação e } \\
\text { Imagem }\end{array}$ & $\begin{array}{l}\text { As Tecnologias de Informação e Comunicação suportam cada vez mais a prestação de } \\
\text { serviços e o relacionamento com clientes e mercado. Os resultados dependem destas } \\
\text { tecnologias, pelo que importa avaliar a eficácia das abordagens. }\end{array}$ \\
\hline $\begin{array}{l}\text { Tratamento de dados } \\
\text { e informações }\end{array}$ & $\begin{array}{l}\text { A evolução para níveis elevados de conectividade entre máquinas e sistemas vai traduzir-se } \\
\text { em volumes de dados, que importar tratar para melhor desenhar os processos e estratégias } \\
\text { de negócio. }\end{array}$ \\
\hline \multicolumn{2}{|r|}{ Custos das Falhas, Perdas e Desperdícios (Riscos) } \\
\hline Subotimização & $\begin{array}{l}\text { Diferenciais entre melhorias parciais e absolutas (ex. apenas as relações cliente-fornecedor, } \\
\text { apenas um processo e não o negócio, sem perspetiva do ciclo de vida). } \\
\text { Otimizações parcelares sem visão holística não permitem níveis elevados de desempenho. } \\
\text { As melhorias nos processos podem traduzir-se em benefícios imediatos, ou apenas } \\
\text { identificar economias potenciais no futuro (ex. libertação de tempos, mas não de recursos). }\end{array}$ \\
\hline Controlo dos riscos & $\begin{array}{l}\text { Avaliação, falhas internas e externas, tais como defeitos, defeituosos, insatisfações, } \\
\text { reclamaçôes. Estes aspetos estão mais cobertos pela experiência anterior, já que decorrem } \\
\text { das abordagens tradicionais. }\end{array}$ \\
\hline Desperdícios & $\begin{array}{l}\text { Sobreprodução, espera, transporte, movimento, processamento em excesso, stocks em } \\
\text { excesso. } \\
\text { Estes tipos de custos podem ser quantificados de algum modo. Contudo, a eliminação de } \\
\text { atividades sem valor acrescentado pode não se traduzir em benefícios económicos diretos, } \\
\text { mas apenas em tempo disponível, pelo que interessa uma quantificação específica. }\end{array}$ \\
\hline $\begin{array}{l}\text { Decorrentes da } \\
\text { estratégia e da } \\
\text { política }\end{array}$ & $\begin{array}{l}\text { Exemplos deste tipo de custos são o excesso de stocks para evitar roturas de fornecimento e } \\
\text { menor taxa de ocupação dos equipamentos. } \\
\text { Para o seu cálculo necessitamos contudo de comparar com a situação ideal. }\end{array}$ \\
\hline $\begin{array}{l}\text { Campanhas de } \\
\text { marketing }\end{array}$ & $\begin{array}{l}\text { Exemplos deste tipo de custos são os produtos produzidos e não vendidos. } \\
\text { Estas atividades especiais de promoção das vendas também podem ser vistos como } \\
\text { oportunidades perdidas. }\end{array}$ \\
\hline
\end{tabular}

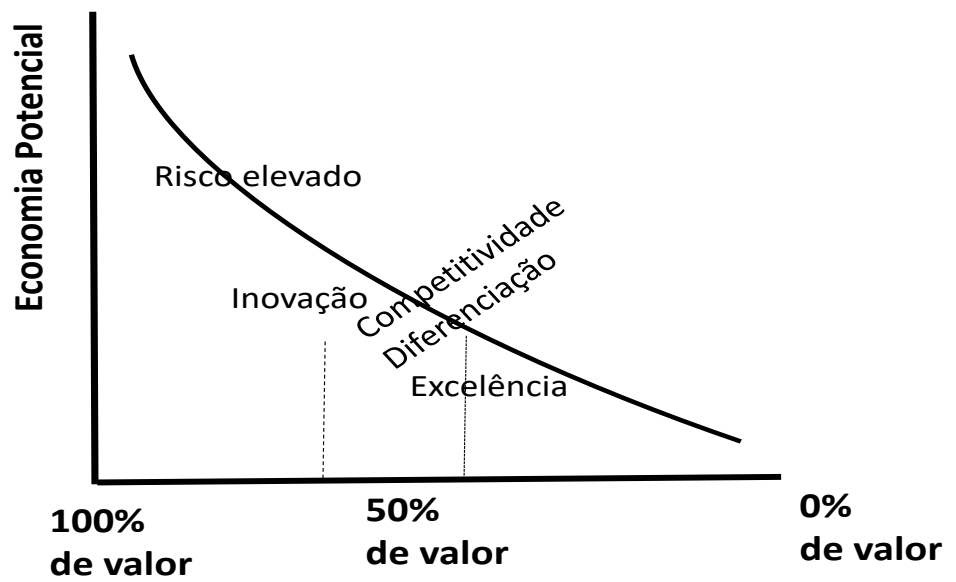

Figura 7: Funções de perda e de ganho

Fonte: Pires (2017) 


\section{CONCLUSÕES E QUESTÕES REMANESCENTES}

As decisões de investir no desenvolvimento da função qualidade necessitam ser suportadas em dados que estimem benefícios suficientes e seguros. Os CRQ podem ajudar a suportar essas decisões.

Os modelos clássicos identificam o designado, erradamente, nível ótimo para a qualidade, ou nível económico para a qualidade, ou seja, indicam ao gestor até onde o retorno é inquestionável. Estes modelos, como tantos outros, têm limitações, que importa entender, para que a sua utilização seja benéfica. Por exemplo, o nível ótimo ou económico da qualidade (para além do qual já não se deve continuar a investir), numa sociedade do conhecimento e da aprendizagem, já não se baseia essencialmente nos custos de investimentos, mas no valor estratégico e no movimento competitivo.

À visão tradicional dos CRQ, útil para explicar a relação entre custos das Falhas e custos de Prevenção e Avaliação, e justificar o investimento na prevenção, num determinado momento, devese contrapor uma visão mais dinâmica, que contemple a melhoria contínua.

Adicionalmente, seria ainda muito importante que as organizações passassem a contabilizar os custos e os benefícios da implementação de técnicas e métodos específicos. Mesmo as grandes empresas multinacionais, com grandes investimentos na implementação de técnicas específicas não contabilizam as relações custos-benefícios, por assumirem que as vantagens são inquestionáveis.

Por outro lado, os custos associados aos processos devem ser outra forma de encarar os CRQ. Eles podem ser vistos em todo o ciclo da qualidade (que tende a coincidir com o ciclo de vida dos produtos e serviços) e não apenas em processos, já na fase de produção e prestação de serviços.

As atividades-chave para alcançar a qualidade (satisfação das necessidades e expetativas dos clientes) deslocam-se cada vez mais para as fases anteriores ao fabrico do produto / prestação do serviço e, principalmente, para a interface da organização com o mercado, onde, pelas técnicas e metodologias mais adequadas, se terá de identificar o que os clientes pretendem; como percecionam a qualidade; e quais as funcionalidades, que os produtos / serviços devem possuir, bem como o preço que eles estão dispostos a pagar.

Os custos incorridos nestas fases não estão suficientemente identificados e relacionados com os resultados. Pelo que, interessa que a técnica dos CRQ se desenvolva e ajude a responder às situações de mudanças, cada vez mais drásticas e frequentes nos produtos e tecnologias, tornando as tarefas dos decisores mais difíceis e arriscadas. Se não existirem dados e informações suficientes, o quadro adensa-se, de tal modo que pode paralisar a organização. Esta realidade levanta a questão de saber que custos devem ser autonomizados e tratados como CRQ nas fases anteriores ao fabrico / prestação do serviço. Dito de outro modo, os custos de desenvolvimento devem todos ser considerados custos de prevenção? Ou dentro dos custos totais, convém autonomizar os custos de prevenção e avaliação e mesmo os das falhas (de projeto)?

De outro ponto de vista, surgem as preocupações com o desenvolvimento sustentável (do ponto de vista do negócio). Os negócios do presente têm de ser geridos de modo a criarem novos negócios para o futuro. Este conceito deve ser complementar ao conceito da sustentabilidade, apenas baseada na preservação dos recursos naturais e do ambiente (Cunha e Cunha, 1999).

Os conceitos anteriores obrigam à satisfação de todas as partes interessadas, e não apenas de algumas, o que implica obter níveis elevados de otimização, eliminando as diversas formas de subotimização. Tradicionalmente, os CRQ envolvem a organização fornecedora e os seus clientes, mas não incluem as outras partes interessadas. Assim, será que as consequências da sua não satisfação devem ser contabilizadas na técnica das CRQ? 
CRQ?

Os custos dos avanços tecnológicos devem também ser incluídos de alguma forma nos

O desenvolvimento sustentável assume um papel central, exigindo uma utilização mais eficaz das novas tecnologias e novas políticas nacionais da ciência e da tecnologia, recentradas prioritariamente na colaboração internacional e na difusão mundial da tecnologia.

Porém, será que os custos da sustentabilidade podem / devem ser autonomizados, ou essa contabilização confundir-se-ia com os da própria sobrevivência?

Considerando somente os estritos termos da lógica de desenvolvimento das organizações, no quadro da sua focalização nos mercados e nos produtos e na otimização dos seus processos, a questão dos CRQ volta a surgir, não em termos táticos, mas estratégicos.

Face ao exposto, as abordagens aos CRQ necessitam de ser repensadas e desenvolvidas para poderem responder às novas realidades. É o caso das alianças. Importa saber que dimensões assumem os CRQ e como podem ser geridos pelos parceiros. Verifica-se que continua a existir uma enorme área cinzenta. Embora se reconheça, sem esforço aparente, que os ativos intangíveis se tornaram (ou estão a tornar) nas maiores fontes de vantagens competitivas, também é certo que não existem técnicas e/ou métodos capazes de descrever adequadamente todos esses ativos intangíveis, e muito menos medir / avaliar / quantificar o valor destes, e ainda mais difícil medir / avaliar / quantificar o valor por eles criado.

Uma das dificuldades reside no facto de os intangíveis não terem, propriamente, valor em si mesmos, (enquanto isolados) apenas fazem sentido no contexto de uma organização em particular e, especificamente, do uso potencial que a organização faça deles. Por outro lado, os aspetos anteriores reforçam-se se se considerar apenas um dos ativos. Eles valem muito mais no seu conjunto. Em muitos casos, apenas apresentarão algum valor, quando considerados em conjunto.

Está-se em presença de um paradoxo? Ou apenas estamos a lidar com contornos de uma novo paradigma organizacional?

Que soluções existem para avaliar as questões relacionadas com a gestão por processos? E com os ativos intangíveis?

Os novos métodos de trabalho e de organização fomentados e suportados nas tecnologias de informação e comunicação levantam questões novas. Pois será que os aspetos e os custos decorrentes destas abordagens podem ser quantificados/avaliados?

Esta situação está bem evidenciada pela afirmação:

"Algumas empresas têm usado a tecnologia da internet para mudar a base da concorrência, afastando-a da qualidade e das características do serviço, fazendo-a através do preço, e com isto tornando mais difícil para qualquer um, na respetiva indústria, ter lucro" (Porter, 2001).

\section{REFERENCIAS}

AKERS, L. Remarks at American Electronics Association Seminar on Quality, Boston, M.A, March $13 ., 1984$.

AMERICAN SOCIETY FOR QUALITY CONTROL, Aircraft-Missile Division. Quality Cost Analysis lmplementation Handbook, Milwaukee, ASQC Press, 1964.

ANTUNES, M. Otimização dos custos relacionados com a qualidade, tese de mestrado, universidade aberta. 1998.

ATKINSON, HAWLEY, HOHNER, G., MUNDT, B., TROXEL, R \& WINCHELL, W. Current Trends in Cost of Quality: Linking the Cost of Quality and Continuous Improvement, Montvale, NJ: National Association of Accountants, 1991. 
BALME, L. The SGS Total Quality Management Window Concept: an lnnovative Aid Toolfor Managers, EOQ, Helsinki., 1993.

BERLINER, C. \& BRIMSORN, J. A. Cost Management for Today's Advanced Manufacturing, Boston: HBS Press, 1988.

BESTER, Y. Net Value Productivity - NVP; A new approach for quality \& productivity economics, $38^{\text {th }}$ EOQ, Lisboa, 1994.

BROOK, R. H. The end of the quality improvement movement: long live improving value. JAMA, v.304, n.16, p.1831-1832, 2010.

BS 6143: Part 1 Guide to the economics of quality: Process cost model, British Standards Institution, London, 1992.

BS 6143: Part 2 Guide to the economics of quality: Prevention, appraisal and failure model, British Standards Institution, London, 1990.

CAMPANELlA, J. Principles of quality costs: Principles, implementation, and use. In ASQ World Conference on Quality and Improvement Proceedings (p. 507). American Society for Quality, 1999.

CAMPANELLA, L. Principies of Quality Costs, $2^{\text {nd }}$ ed., Milwaukee, American Society for Quality Control. 1990.

CROSBY, P. B. Quality is Free, McGraw-Hill, New York, 1979.

CUNHA, J.V \& CUNHA, M.P (1999), “Organização: Tese, antítese e síntese”, em M.P Cunha (1999c), Teoria Organizacional, Publicações Dom Quixote, pp.437-470.

DALE, B.G. \& PLUNKETT, J. Quality Costing, $2^{\text {nd }}$ ed. Chaprnan \& Hall, 1995.

DANFORTH, D. A Common Commitment to Total Quality, Quality Progress, January, pp. 17, 1986.

DAWES, E. W., \& CAMPANELLA, J. Quality costs. New concepts and methods. Quality cost: ideas and applications, 2, 1989.

DEMING, W.E. Out of the Crisis: Quality, Productivity and Competitive Position, Cambridge, MA, Massachusetts Institute of Technology, Center of Advanced Engineering Study, 1982.

DOMINGUES, J.P., REQUEIJO, J., \& CABRITA, M. R. Reducing Production Costs by Applying Lean Six Sigma Methodolgy: A Case Study. TMQ_Techniques Methodologies and Quality, Número especial, p.25-46, 2016.

FEIGENBAUM, A. V. Total quality-control. Harvard business review, v.34, n.6, p.93-101, 1956.

FEIGENBAUM, A.V. The Challenge of Total Quality Control. Industrial Quality Control, May, p.17, 22-23, 1957.

FINE, C.H. Quality Improvement and Leaming m Production Systems. Management Science, October, p.1301-1315, 1986.

HOWELL, R. \& SOUCEY S. Operating Controls in the New Manufacturing Environment. Management Accounting, October, p.25-31, 1987.

JENSEN, C.M. \& MECKLING, W.H. Specific and general knowledge and organizational structure. Journal of Applied Corporate Finance, v.8, n.2, p.17-38, 1995.

JURAN, J.M. \& GRYNA, F.M. Quality Planning and Analysis. $3^{\text {rd }}$ ed., McGraw-Hill, 1993.

JURAN, J.M. Section 1, The Econornics of Quality. Quaiity Control Handbook, New York: McGraw-Hill, 1951.

JURAN, J.M. Juran on Planning for Quality, The Free Press, 1988.

JURAN, M. \& GRYNA, F.M. Quality Planning and Analysis. $3^{\text {rd }}$ ed., New York: McGraw-Hill, 1993.

KAPLAN, R. S. Measurement Manufacturing Performance: A New Challenge for Managerial Accounting Research", The Accounting Review, October, p.686-705, 1993.

KAPLAN, R. S. Yesterday Accounting Undermines Production. Harvard Business Review, July-August, p. 95-101, 1984.

KHANDEKAR, A. S., \& SULAKHE, V. N. Six Sigma-The revival Of TQM. International Journal of Mechanical Engineering and Robotics Research, v.3, n.1, p.50-58, 2014.

LILLRANK, P. \& KANO, N. Continuous Improvement - Quality circles in japanese industry, Center for Japanese Studies, University of Michigan, 1989.

MASSER, W. J. The Quality Manager and Quality Cost. Industrial Quality Control, October, p.5-8, 1957.

MILLAR, R.M. Breakpoint Business Process Engineering, EOQ, He1sinki, 1993.

MONTGOMERY, D. C. Statistical Quality Control, John Wiley \& Sons, Inc, 2009.

MORSE, W.J., ROTH, H.P. \& POSTON, K.M. Measuring, Planning, and Controlling Quality Costs, Institute of Management Accountants/ ASQC Quality Press, Milwaukee, 1987.

MURRAY, R. J. The Quest For World Class It Capability It Is Key to Achieving Quality Goals. Information System Management, v.8, n.3, p.7-15, 1991.

NAKAGAWA, M. Gestão Estratégica de Custos: Conceitos, Sistemas e lmplementação, Editora S.A., São Paulo, 1991.

NP 4239 Bases para a quantificação dos custos da qualidade, Instituto Português da Qualidade, 1994

PEREIRA, L., TENERA, A., \& WEMANS, J. Insights on Individual's Risk Perception for Risk Assessment in Web-based Risk Management Tools. Procedia Technology, v.9, 886-892, 2013.

PIRES, A. R. Sistema da Qualidade e Situação Económica", Qualidade, Dezembro, p.12-14, 1993.

PIRES, A.M.R. Sistemas de Gestão da Qualidade, Edições Sílabo, Lisboa, 2016. 
PIRES, A.M.R. Revisitando os custos relacionados com a qualidade”, Atas do 13 CIBEM 2017, Artigo $144,2017$.

PIRES, A.R, NOVAS, J. SARAIVA, M. \& COELHO, A. How companies use the information about quality-related costs", Total Quality Management \& Business Excellence, v.28, n.5, p.501-521, 2017.

PLUNKETT, J.J. \& DALE B.G. A Review of the Literature on Quality Related Costs. International Journal o] Quality and Reliability Management, v.4, n.1, p 40-52, 1988.

PORTER, M. Strategy and Internet. Harvard Business Review, march, p.63-79, 2001.

ROONEY, E. M. \& ROGERSON, H. Simpliquality, A self-appraisal kit for identifying and measuring quality related costs in manufacturing industry, The Chartered Institute of Management Accountants, Londo, 1991.

RUTHERFORD, G. Quality Control in Industry Methods and Systems, New York, Pitman Publishing Corpo, 1948.

SALVADA, P., CARNEIRO, M., \& MOURÃO, A. The lean thinking application in aircraft maintenance. TMQ_Techniques Methodologies and Quality, Número especial, p.65-85, 2016.

SCHNEIDERMAN, A. M. Optimum Quality Costs and Zero Defects: Are They Contradictory Concepts?. Quality Progress, November, p.28-31, 1986.

SCHNEIDERMAN, A. M. Setting Quality Goals, Quality Progress, April, p. 51-57, 1988.

SIMPSON, B. \& MUTHLER D. L. Quality Costs: Facilitating the Quality lnitiatives, Journal of Cost Management, Spring, p.25-34, 1987.

SMITH, W.B. Total Customer Satisfaction, EOQ, Helsinki, 1993.

SULliVAN, E. E., OWENS, D. A. Catching a glimpse of quality costs today Quality Progress, December, p. 21-24, 1983.

SUZAKI, K. Gestão de Operações Lean: Metodologias Kaizen para a Melhoria Contínua. LeanOp. Inc. Mansores, Portugal, 2010.

TAGUCHI, G. System of Experimental Design, (VoIs 1 e 2), UnipublKraus International, 1987.

TASSINARI, M. L' analyse de la valeur dans la constrution de la Qualité; 29 Conference, EOQ, 1981. 